\title{
Microencapsulated Ferrous Sulfate to Fortify Cow Milk: Absorption and Distribution in Mice
}

\author{
José R. Boccio, * Marcela B. Zubillaga, Ricardo A. CARo, \\ Alexis E. LysioneK, María J. Salgueiro, \\ Gabriela P. Calmanovici, María I. SARabia \\ and Ricardo WEILL ${ }^{1}$ \\ Radioisotope Laboratory, Physics Department, School of Pharmacy and Biochemistry, \\ University of Buenos Aires, Jurín 956, 1113-Buenos Aires, Argentina \\ ${ }^{1}$ Center of Research and Development, La Serenisima, \\ Buenos Aires, Argentina \\ (Received September 12, 1997)
}

\begin{abstract}
Summary To determine the absorption and biodistribution of iron from microencapsulated ferrous sulfate (SFE-171), used to fortify dairy products with iron, a comparative study in four groups of 30 mice each was carried out. In two of the groups, the absorption of iron from ferrous ascorbate in water $(13.3 \pm 4.3 \%)$ and from ferrous sulfate in water $(12.7 \pm 3.9 \%)$ was determined and taken as reference standards. In the third group the iron absorption from SFE-171 in milk was determined, giving a value of $12.1 \pm 4.2 \%$, which statistically does not differ from the data obtained with either reference standard. In the fourth group, the absorption of iron from ferrous sulfate in milk showed a value of $7.7 \pm 3.4 \%$, which statistically differs with a $p<0.01$ from the data corresponding to the other three groups. The biodistribution studies showed that the iron from SFE-171 follows the same metabolic pathway as the iron from the reference standards thus, giving a higher radioactivity percentage and radioactivity concentration in organs or systems, principally blood, that are closely related to iron metabolism. Our studies allow us to conclude that the iron from SFE-171 in milk follows the same behavior as the nonhemic iron, with a higher absorption than that of ferrous sulfate in milk.
\end{abstract}

Key Words milk, fortification, iron, metabolism, absorption

Since iron deficiency is one of the most frequent nutritional problems, different strategies have been elaborated to overcome it. Food fortification has been demonstrated to be the most effective and the least costly solution. A World Bank

\footnotetext{
* To whom correspondence should be addressed.
} 
economic analysis clearly demonstrates the economic, health, and social benefits from the prevention of this deficiency, showing that in those countries with a high incidence of this and other nutritional deficiencies, such as those of iodine and vitamin A, losses attributable to incapacities and deaths represent $5 \%$ of the Gross National Product (GNP). The solution of the problem by means of food fortification represents only $0.3 \%$ of the GNP (l).

The fortification of food with iron should take into account several factors. The food used as the carrier of this micronutrient should be widely used by the risk groups. The most-used foods are cereals and lacteous products; in a lower proportion, salt, sugar, coffee, and condiments are also used. The iron source should have a high bioavailability, with no alterations of the sensorial characteristics of the food, and no interactions between the nutritional matrix and the iron source as a consequence of its chemical reactivity should result (2).

For a long time, many efforts have been undertaken to fortify milk with iron, taking into account that this food has a low iron content of less than $1 \mathrm{mg}$ per $\mathrm{L}$ and that it is consumed by children, one of the principal risk groups. The principal problem is the severe alteration of the sensorial characteristics of the food. Moreover, a strong reciprocal interaction between iron and nutrients in milk produces the oxidation of its unsaturated fatty acids and consequent rancidity; the oxidation of vitamins and amino acids determines a significant decrease of the nutritional value of the food and important alterations of its sensorial characteristics, making it unacceptable for consumption.

Nowadays, it is possible to fortify cow milk with iron by a new technological procedure in which ferrous sulfate is microencapsulated with phospholipids and added to the milk. In this way, the interaction between iron and food is avoided, and consequently the undesirable effects described above can be prevented. In previous publications we evaluated different patterns of this new iron source called SFE-171 (3-7). In this work, we studied the iron absorption and biodistribution in mice to determine its metabolism when this new iron source is used for the fortification of cow milk.

\section{MATERIALS AND METHODS}

We used 120 female Swiss strain mice, 5 mo old, with weights ranging from 30 to $35 \mathrm{~g}$. They were maintained in four groups of 30 mice each in stainless steel cages $315 \mathrm{~mm} \times 445 \mathrm{~mm} \times 240 \mathrm{~mm}$ with grated floors and collection trays of stainless steel, thus preventing the feces to come into contact with the animals. They had free access to water and were nourished with a normalized diet (Nutrimentos ${ }^{\mathrm{TM}}$ diet No. 3). The animals were maintained with cycles of $12 \mathrm{~h}$ of light and $12 \mathrm{~h}$ of darkness throughout the experiment.

$\dagger$ Japanese patent $\# 178712 / 94$. SFE stands for stabilized ferrous sulfate in Spanish; 171 is the number of the experiment. 
Before the administration of the products, the animals were deprived of any solid food for $10 \mathrm{~h}$; food was restored $1 \mathrm{~h}$ after the product intake. The preparations were administered by means of a syringe coupled to a plastic catheter, which allowed the standardization of the intake volume at $0.1 \mathrm{~mL}$. For product labeling, ${ }^{59} \mathrm{Fe}$ (NEN, Du Pont, catalogue No. NEZ 037) was used. In all cases, we used pasteurized whole cow milk, which has $3 \mathrm{~g} / 100 \mathrm{~mL}$ of fat, $3.1 \mathrm{~g} / 100 \mathrm{~mL}$ of protein, $4.7 \mathrm{~g} / 100 \mathrm{~mL}$ of carbohydrates, $0.12 \mathrm{~g} / 100 \mathrm{~mL}$ of calcium, and $0.09 \mathrm{~g} / 100 \mathrm{~mL}$ of phosphorus; furthermore, it is fortified with 200 I.U. of vitamin $\mathrm{A} / 100 \mathrm{~mL}$ and 40 I.U. of vitamin $\mathrm{D} / 100 \mathrm{~mL}$.

For the bioavailability studies, $4 \mu \mathrm{g}$ of iron and $111 \mathrm{kBq}(3 \mu \mathrm{Ci})$ of ${ }^{59} \mathrm{Fe}$ were administered per mouse for all the products. Each of the four groups received one of the following preparations: ferrous sulfate in milk, SFE-171 in milk, ferrous sulfate in water, and ferrous ascorbate in water. These last two preparations were used as reference standards. The standard of aqueous ferrous ascorbate was prepared with ferrous sulfate and ascorbic acid with a molar ratio of $\mathrm{Fe}$ /ascorbic acid equal to 1 . The ferrous sulfate solution was freshly prepared with bidistilled water under nitrogen atmosphere. The samples of ferrous sulfate and SFE-171 in milk were prepared by adding each compound to the whole milk and heating the samples at $100^{\circ} \mathrm{C}$ for $30 \mathrm{~min}$.

The absolute activity of each sample was determined by means of an ionization chamber (RADX Model 255 Remote). The activity retained by each mouse as a function of time was measured in a gamma spectrometer with a $5 \mathrm{~cm} \times 5 \mathrm{~cm} \mathrm{NaI(Tl)}$ well crystal in optimal electronic conditions. The ${ }^{59} \mathrm{Fe}$ radioactivity retained by each mouse was measured as a function of time by using a whole-body geometry, introducing each animal in a covered lucite box, the size of which was similar to that of the animal and adequate to the detector geometry. In this way, detection errors attributed to eventual movements of the animal could be minimized. The iron retention for each mouse was determined, and a curve of retention percentage as a function of time was constructed for each one. The iron absorption was determined by the extrapolation of the final portion of the curve of percentage of iron retention as a function of time. This final portion was extrapolated to the initial time $(t=0)$ by means of a linear regression analysis of the experimental data to eliminate the physical radioisotopic decay and the physiological loss (Fig. 1).

Biological distributions were carried out $15 \mathrm{~d}$ after the administration of the different iron sources to determine the iron biodistribution once the metabolic cycle had been completed. The mice received i.v. 1,500 I.U. of heparin per $\mathrm{kg}$ body weight and were then anesthetized with ethyl ether and finally bled by means of retroorbital sinus puncture; about $1 \mathrm{~mL}$ of blood was collected from each mouse. The ${ }^{59} \mathrm{Fe}$ activity of $0.5 \mathrm{~mL}$ blood sample was determined, and the red blood cells were then separated from plasma by centrifugation, washed twice with isotonic saline solution, and measured again. These determinations were carried out by measuring ${ }^{59} \mathrm{Fe}$ gamma rays as described above. The liver, spleen, the whole carcass, the gut with its contents, lungs, heart, brain, uterus, and kidneys were then removed, 


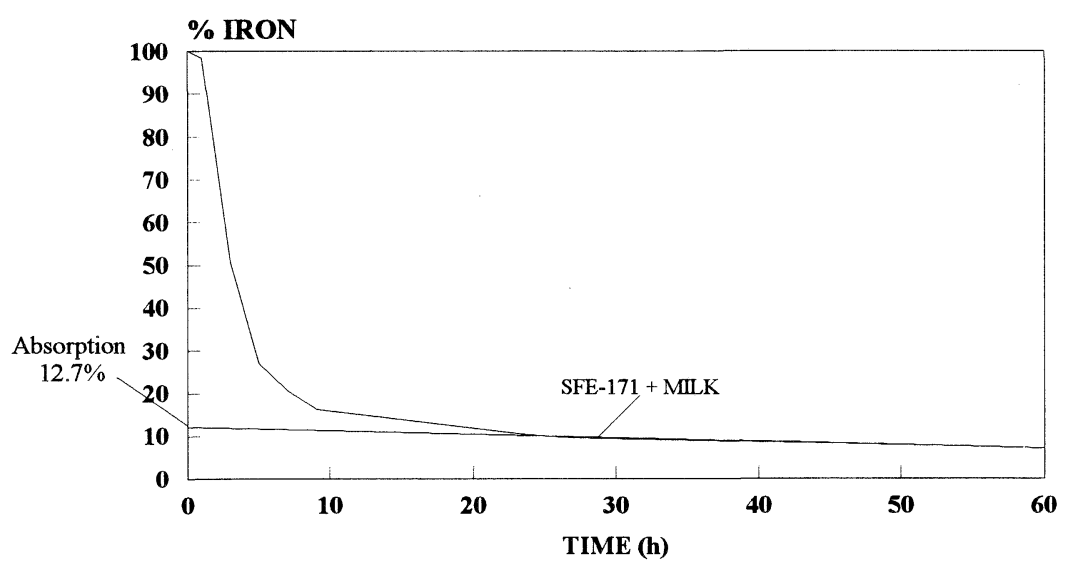

Fig. 1. Percentage of iron retention as a function of time for one mouse that received SFE-171 in milk. Notice that the final portion of the curve was extrapolated to time $=0$ to eliminate the physical radioisotopic decay and the physiological loss. This procedure was applied to each mouse to determine the individual iron absorption.

washed with isotonic saline solution, and then the activity was determined in a similar way. The results are given as the percentage of the retained radioactivity in each organ or tissue $(A \%)$ and as the percentage of the radioactivity concentration, $C \%$, i.e., $(A / w) \%$, where $w$ is the weight of each organ or tissue.

To verify the hematological pattern of the different groups and to confirm their normal iron balance, the blood parameters (hematocrit, hemoglobin, and FEP) were determined and compared between the different groups of mice. The hematocrit was determined by the micromethod, the hemoglobin by Drabkin's technique, and the free erythrocyte protoporphyrin (FEP) by a ZP Hematofluorometer AVIV Model 206D (8).

The data are presented as mean $\pm \mathrm{SD}$. The results were evaluated by a one-way analysis of variance (ANOVA). To test the differences among the means, the Student-Newman-Keuls method was used. Only the probability levels $<0.01$ were considered to be statistically significant $(9)$.

\section{RESULTS}

The absorption values of SFE-171 and of the other iron sources used for comparative purposes are shown in Table 1. The absorption of SFE-171 in milk $(12.1 \pm 4.2 \%)$ does not differ significantly from the values obtained with the reference standards, ferrous ascorbate in water $(13.3 \pm 4.3 \%)$ and ferrous sulfate in water $(12.7 \pm 3.9 \%)$. The absorption of ferrous sulfate in milk $(7.7 \pm 3.4 \%)$ was significantly lower $(p<0.01)$ than that of the other three groups.

Table 2 shows the biodistribution results obtained with each iron source $15 \mathrm{~d}$ 
Table 1. Iron absorption from different iron sources.

\begin{tabular}{ccccc}
\hline Iron source & $\begin{array}{c}\text { Ferrous ascorbate } \\
\text { in water }\end{array}$ & $\begin{array}{c}\text { Ferrous sulfate } \\
\text { in water }\end{array}$ & $\begin{array}{c}\text { Ferrous sulfate } \\
\text { in milk }\end{array}$ & $\begin{array}{c}\text { SFE-171 } \\
\text { in milk }\end{array}$ \\
\hline $\begin{array}{c}\text { Absorption } \% \pm \text { SD } \\
\text { Number of animals }\end{array}$ & $\begin{array}{c}13.3 \pm 4.3 \\
30\end{array}$ & $\begin{array}{c}12.7 \pm 3.9 \\
30\end{array}$ & $\begin{array}{c}7.7 \pm 3.4^{*} \\
30\end{array}$ & $\begin{array}{c}12.1 \pm 4.2 \\
30\end{array}$ \\
\hline
\end{tabular}

${ }^{1}$ Molar ratio ascorbic acid/iron $=1 .{ }^{2}$ Under nitrogen atmosphere. ${ }^{3}$ Heated $30 \mathrm{~min}$ at $100^{\circ} \mathrm{C}$.

* Value statistically different for the other groups $(p<0.01)(n=30)$.

after its administration. The highest percentage of absorbed iron is found in blood. In decreasing order we find the iron was absorbed by the carcass (muscle, skin, and bones) and by the liver. We could not observe any statistically significant difference among the percentages of iron absorption from SFE-171 in any organ or tissue in comparison with the reference standards.

Table 3 shows that the percentage of radioactivity concentration values are the highest in blood, liver, and spleen, which are the tissues and organs that have a predominant role in iron metabolism. Moreover, we found that after the red blood cell (RBC) washing procedure, the total activity was localized in RBC. No statistically significant difference among the studied iron sources in any tissue or organ could be detected.

Table 4 shows the hematocrit, hemoglobin, and FEP values for each group. No statistically significant difference could be found in any of the evaluated parameters.

\section{DISCUSSION}

The composition of the nutritional matrix of milk induces a strong decrease of iron absorption. Our experimental results, as shown in Table 1, demonstrate that ferrous sulfate in milk has a statistically significant $(p<0.01)$ lower absorption than the reference standards and SFE-171 have. The iron absorption from this last product has shown no statistically significant difference than in the case of the reference standards. It seems worthwhile to further analyze this inhibitory action of milk on iron absorption. Casein is a principal milk protein, being a phosphoprotein that oxidizes $\mathrm{Fe}^{2+}$ to $\mathrm{Fe}^{3+}$, thus producing insoluble compounds in milk that significantly decrease iron bioavailability. The enzymatic removal of the phosphate groups of casein reverts this situation, demonstrating its participation in the process. Other milk proteins, like $\beta$-lactoglobulin and $\alpha$-lactoalbumin, both of them milk whey constituents and none of them phosphoproteins, also decrease iron bioavailability by a still unknown mechanism. The enzymatic hydrolysis of these proteins produces a significant increase on iron bioavailability. However, this procedure determines severe alterations of the sensorial characteristics of the food, 


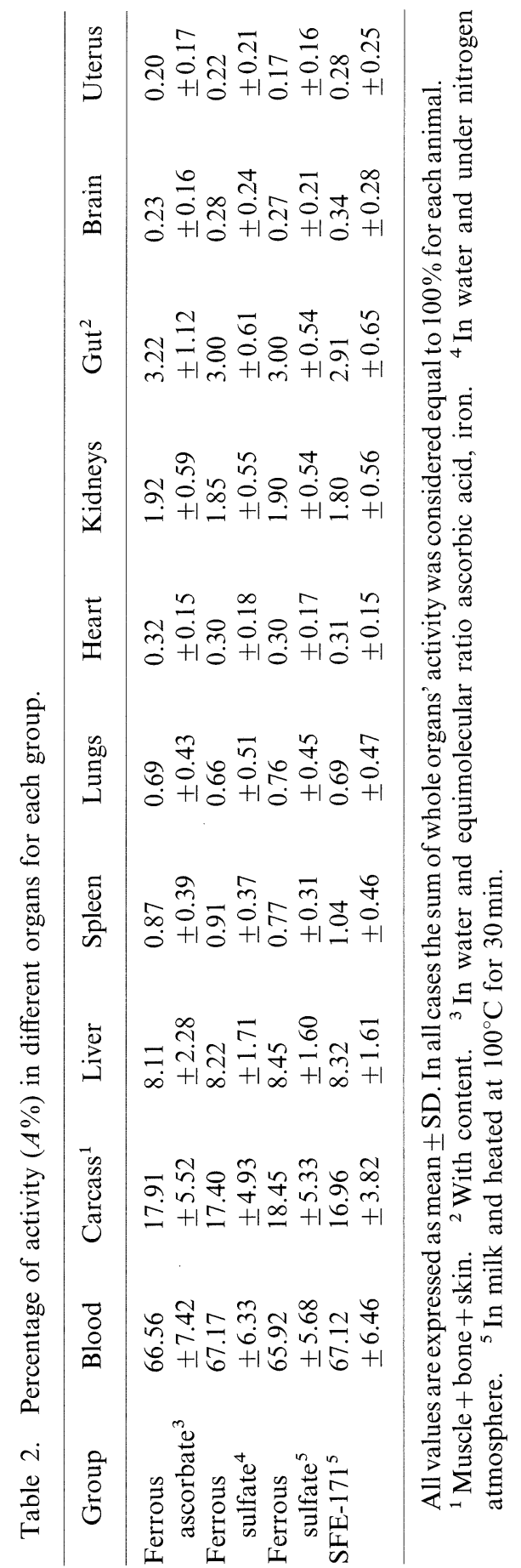

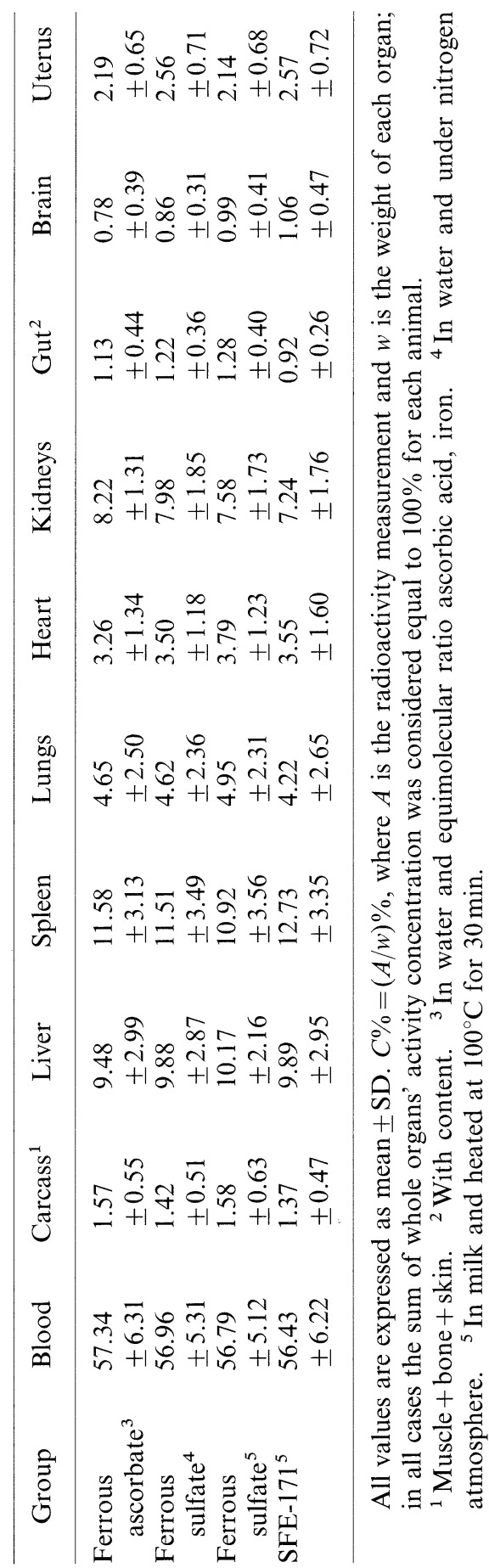


Table 4. Hematological patterns for different animal groups.

\begin{tabular}{lccc}
\hline \multicolumn{1}{c}{ Group } & $\begin{array}{c}\text { Hematocrit } \\
(\%)\end{array}$ & $\begin{array}{c}\text { Hemoglobin } \\
(\mathrm{g} / \mathrm{dL})\end{array}$ & $\begin{array}{c}\mathrm{FEP}^{3} \\
\left(\mu \mathrm{g} / \mathrm{dL} \mathrm{RBC}^{4}\right)\end{array}$ \\
\hline Ferrous ascorbate $^{1}$ & $49.9 \pm 0.8$ & $15.2 \pm 0.7$ & $70.3 \pm 3.8$ \\
Ferrous sulfate $^{1}$ & $50.1 \pm 0.9$ & $14.9 \pm 0.6$ & $69.8 \pm 4.1$ \\
Ferrous sulfate $^{2}$ & $49.5 \pm 1.3$ & $15.1 \pm 0.9$ & $71.1 \pm 3.5$ \\
SFE-171 $^{2}$ & $50.1 \pm 1.2$ & $15.1 \pm 0.8$ & $69.6 \pm 3.8$ \\
\hline
\end{tabular}

All values are expressed as mean $\pm \mathrm{SD}$. None of the cases showed a statistically significant difference. These hematological results demonstrate the homogeneus iron state of the different experimental groups.

${ }^{1}$ In water. ${ }^{2}$ In milk. ${ }^{3}$ Free erythrocyte protoporphyrin. $\quad{ }^{4}$ Red blood cells.

making it unacceptable for consumption (10-13).

Phosphates and calcium are important constituents of milk and potential inhibitors of iron absorption. Phosphates produce insoluble salts principally with $\mathrm{Fe}^{3+}$, consequently avoiding its absorption. In the case of calcium, some contradictions are noted with regard to the degree of its inhibitory effect and the mechanism by which it interferes with the iron absorption. Minotti et al (14) studied the effect of different calcium sources on iron absorption in rats, demonstrating that the chemical form of the calcium source and the physiological conditions of the animals are determinate factors for iron absorption. Deehr et al (15) studied the effect of calcium sources such as calcium citrate malate or milk on iron absorption in postmenopausal women, finding that in the case of milk the inhibitory effect on iron absorption is more important. However, as mentioned above, milk contains proteins that also have an inhibitory effect on iron absorption, which cannot be neglected.

Even though bioavailability is an important parameter for the study of an iron source for food fortification, determining that this iron has a metabolic and physiological behavior similar to that of the iron provided naturally by foods is also important. For this purpose the biodistribution studies of iron were carried out. Table 2 shows the activity percentage $(A \%)$ for each iron source and tissue. Since only the used iron source is labeled with ${ }^{59} \mathrm{Fe}$, the measured radioactivity indicates the metabolic behavior of the iron provided by this source. The highest percentage is found in the tissues related to iron metabolism; in blood, values of nearly $70 \%$ were found. The results indicate that all the radioactivity was in red blood cells. In a smaller proportion than in blood, iron was also found in the carcass, formed by the muscles, bones, and skin. Approximately $8 \%$ of the absorbed iron is found in liver, a tissue that regulates the homeostasis of this element and in which iron is stored as ferritin or its aggregated form, hemosiderin. Even though in the remaining tissues we found a smaller activity percentage, their iron content has important functions, since it is included in biomolecules that are metabolically 
essential for these tissues (16-18). In no case could we observe any statistically significant difference in the activity percentage of any organ with regard to the iron source.

To solve the influence of the weight of any tissue on the iron distribution, the data are given as activity concentration percentage, $C \%$. Table 3 shows that the highest $C \%$ values are again obtained in blood. Unlike the data shown in Table 2 , however, the spleen, an organ related to iron metabolism, has a remarkable value from $10 \%$ to $12 \%$. In the same sense, the kidneys have a relevant value close to $8 \%$ as a consequence of the cytochromes present in these organs. Liver also shows an important $C \%$ value. It is interesting to point out that even though iron in the brain has important functions, the $C \%$ of this organ is the smallest value for this parameter. This may be due to the low turnover rate of the iron pool in this tissue in the case of adult animals. From the statistical point of view, none of the $C \%$ values demonstrated a significant difference for any of the studied iron sources in each tissue or organ.

The absorption and metabolism of iron are significantly affected by the nutritional status of the organism for this element. Therefore it is important to demonstrate in a comparative study that all the animals have the same nutritional status for this micronutrient. For this purpose, hematological studies were carried out in each animal of the different groups. As shown in Table 4, no case showed a statistically significant difference for any of the studied parameters, demonstrating the homogeneity of the nutritional status for iron of the different groups.

Our results allow the conclusion that the iron supplied by SFE-171 in milk has the same metabolic behavior as nonhemic iron and a higher bioavailability than ferrous sulfate in milk.

We want to acknowledge herewith the kind assistance of Mrs. Carlos Gotelli and Mariano Gotelli, biochemists at the Center of Toxicological Research, for the hematological studies carried out in this work.

\section{REFERENCES}

1) Enriching Lives, Overcoming Vitamin and Mineral Malnutrition in Developing Countries. 1994. The International Bank for Reconstruction and Development. The World Bank.

2) Hurrel R. 1997. Preventing iron deficiency through food fortification. Nutr Rev 55: 210-222.

3) Boccio J, Zubillaga M, Caro R, Gotelli C, Gotelli M, Weill R. 1995. New procedure to fortify fluid milk and derivatives with iron. A comparative study in mice. $J$ Nutr Sci Vitaminol 41: 619-626.

4) Zubillaga M, Caro R, Boccio J, Gotelli C, Gotelli M, Weill R. 1996. New procedure to fortify fluid milk with iron: Metabolic and biochemical study in rats. Nutr Res 16: 131-137.

5) Boccio J, Zubillaga M, Caro R, Gotelli C, Gotelli M, Weill R. 1996. Bioavailability and stability of microencapsulated ferrous sulfate in fluid milk. J Nutr Sci Vitaminol 
42: 233-239.

6) Boccio J, Zubillaga M, Caro R, Gotelli C, Gotelli M, Weill R. 1998. Bioavailability, absorption mechanism and toxicity of microencapsulated iron(II) sulfate. Studies in mice. Biol Trace Element Res 62: 65-73.

7) Boccio J, Zubillaga M, Caro R, Gotelli C, Gotelli M, Weill R. 1997. New procedure to fortify fluid milk and dairy products with high-bioavailable ferrous sulfate. Nutr Rev 55: 240-246.

8) Bernard Henry J. Todd-Sanford-Davidsohn. 1988. Clinical Diagnosis and Management by Laboratory Methods, 17th ed, WB Saunders, Philadelphia.

9) Sokal RR, Rohlf FJ. 1969. Biometry, WH Freeman, San Francisco.

10) Hurrell RF, Lynch SR, Trinidad PT, Dassenko SA, Cook J. 1989. Iron absorption in humans as influenced by bovine milk proteins. Am J Clin Nutr 49: 546-552.

11) Beltiz HD, Grosch W. 1987. Food Chemistry, Springer Verlag, Berlin.

12) Emery T. 1992. Iron oxidation by casein. Biochem Biophys Res Commun 182: 1047-1052.

13) Carmichael D, Christopher J, Hegenauer J, Saltman P. 1975. Effect of milk and casein on the absorption of supplemental iron in the mouse and chick. Am J Clin Nutr 28: 487-493.

14) Minotti PL, Buchonski SM, Miller DD. 1993. Effects of calcium supplementation, calcium source and lactose on iron absorption in the rat. Nutr Res 13: 1173-1181.

15) Deehr MS, Dallal GE, Smith KT, Taulbee JD, Dawson-Hughes B. 1990. Effects of different calcium sources on iron absorption in postmenopausal women. Am J Clin Nutr 51: 95-99.

16) Dallman PR. 1990. Iron. Present Knowledge in Nutrition, 6th ed, International Life Sciences Institute, Washington.

17) Goodman Gilman A. 1996. The Pharmacological Basis of Therapeutics, Pergamon Press, New York.

18) Lehninger A, Nelson D, Cox M. 1993. Principles of Biochemistry, Worth Publishers, New York. 